\title{
1 Tensile testing to quantitate the anisotropy and strain hardening of mozzarella
}

2 cheese

3 Ramona Bast ${ }^{a}$, Prateek Sharma ${ }^{a, b}$, Hannah K. B. Easton ${ }^{a}$, Tzvetelin T. Dessev ${ }^{a}$, Mita Lad ${ }^{a, c}$

4 and Peter A. Munro ${ }^{a, *}$

$5 \quad{ }^{a}$ Riddet Institute, Massey University, Private Bag 11 222, Palmerston North 4442, New Zealand

$6 \quad{ }^{b}$ National Dairy Research Institute, Karnal-132001, Haryana, India

${ }^{c}$ Fonterra Research and Development Centre, Private Bag 11 029, Palmerston North 4442, New Zealand

$8 \quad *$ Corresponding author. Tel.: +6463504986

$9 \quad$ E-mail address: p.a.munro@massey.ac.nz

\section{ABSTRACT}

11 We explored anisotropy of mozzarella cheese because some studies reported anisotropy whereas others looked for anisotropy and failed to find it. Tensile testing proved to be a good method because the location and mode of failure were clear. Mozzarella cheese cut direct from the block showed no significant anisotropy though confocal microscopy showed good structure alignment at a microscale. Deliberately elongated mozzarella cheese showed strong anisotropy with tensile strength in the elongation or fibre direction about 3.5 times that perpendicular to the fibres. Temperature of elongation had a marked impact on anisotropy with maximum anisotropy after elongation at $70^{\circ} \mathrm{C}$. We suggest the disagreement on anisotropy in the literature is related to the method of packing the mozzarella cheese into a block after the stretching stage of manufacture. Tensile stress/strain curves in the fibre direction showed marked strain hardening with modulus just before fracture about 2.1 times that of the initial sample, but no strain hardening was found perpendicular to the fibre direction. 


\section{Introduction}

A hot-water stretching and working step forms part of the production of mozzarella cheese. In this step the proteins in the cheese curds coalesce into larger protein strands oriented in the direction of stretching, resulting in a typical fibrous microstructure based on protein networks (McMahon, Fife \& Oberg, 1999). This fibrous structure is also visible on a macroscopic level, for instance by tearing the cheese manually along its fibres. This fibrous structure suggests the likelihood of anisotropy, i.e. physical and mechanical properties dependent on the direction of examination. However, the literature on mozzarella cheese anisotropy is conflicting. Cervantes, Lund and Olson (1983) used compression tests and reported anisotropy in some samples but not in others. Ak and Gunasekaran (1997) found anisotropy using tensile testing whereas others specifically looked for anisotropy and did not find it (Muliawan \& Hatzikiriakos, 2007, using an extensional rig similar to tensile testing; Olivares, Zorrilla \& Rubiolo, 2009, using creep/recovery tests). No attempt was made in these later papers to explore or discuss the reasons for the differences with earlier work.

Rheological properties are closely related to the functional characteristics of melted mozzarella cheese such as meltability, stretchability, elasticity, oiling-off and browning. The orientation of protein fibres is expected to impact in particular the melting and stretching properties of mozzarella cheese (Kindstedt \& Fox, 1993) suggesting a correlation between the extent of anisotropy and the functional characteristics of mozzarella cheese. Olivares et al. (2009) also suggest that the extent of anisotropy is related to the functionality of mozzarella cheese.

Anecdotal experience suggests that mozzarella cheese shows work thickening or strain hardening behaviour or both. For example the stretching or working step in the manufacture process makes the cheese mechanically stronger. Strain hardening is defined as the phenomenon in which the stress required to deform a material increases more than proportionally to the strain - at constant strain rate and increasing strain (Kokelaar, van Vliet \& Prins, 1996; Van Vliet, 2008). Work thickening is a broader term and we use it for an increase in mechanical strength when a material is worked. To the best of our knowledge no work thickening or strain hardening behaviour has been 
reported for mozzarella cheese or for any other cheese. Strain hardening has, however, been reported for fine stranded whey protein isolate gels (Lowe, Foegeding \& Daubert, 2003), for weak $\beta$-lactoglobulin gels (Pouzot, Nicolai, Benyahia \& Durand, 2006) and for gels formed by acidifying transglutaminase cross-linked casein (Rohm, Ullrich, Schmidt, Lobner \& Jaros, 2114). For some texturizing proteins, such as gluten in wheat dough, strain hardening is well explored. In wheat dough strain hardening plays an important role in the gas holding capacity, the gas cell stability and the extension behaviour during fermentation and baking. The strain hardening behaviour of wheat dough is also related to breadmaking performance (Kokelaar et al., 1996; Van Vliet, Janssen, Bloksma \& Walstra, 1992). Mozzarella cheese has some similarities in mechanical behaviour to bread dough suggesting that it could exhibit strain hardening.

We began our study with three hypotheses that if true might help to explain the conflict in the literature: 1. Extent of anisotropy depends on the degree of alignment of the fibrous cheese structure; 2. Melting the cheese would remove alignment of protein fibres and so remove anisotropy; 3. Holding the cheese at an elevated temperature (but below melting temperature) would reduce alignment and decrease anisotropy. The studies referred to above all evaluated mechanical properties of mozzarella cheese slices cut directly from the block. In addition to this methodology we decided to use deliberate elongation of the mozzarella cheese to induce fibre formation in the direction of elongation. If hypothesis 1 is true this fibre formation should lead to anisotropy. We considered various methods of elongation and decided on manual rolling because of its simplicity and because Muliawan and Hatzikiriakos (2008) had used rolling. Tensile tests were chosen for three reasons - they are easier to interpret because fracture location is clear, there are no complicating factors such as friction or change in sample orientation under load, and analysis of tensile stress-strain curves should indicate strain hardening if it is present. Tensile fracture in the cheese fibre direction is assumed to fracture the fibres themselves. Tensile fracture perpendicular to the protein fibre direction is more likely to cause fracture between the protein fibres. 


\section{Materials and methods}

\subsection{Materials}

Mozzarella cheese directly from a Fonterra cheese plant in New Zealand (named "factory cheese") was obtained as two $10 \mathrm{~kg}$ blocks frozen at $-20^{\circ} \mathrm{C}$. The cheese had been frozen at the age where its functionality was optimal for application as pizza cheese. The $10 \mathrm{~kg}$ blocks were thawed for $3 \mathrm{~d}$ at $4{ }^{\circ} \mathrm{C}$, cut into smaller blocks of $\sim 300 \mathrm{~g}$, vacuum-packed into plastic bags and stored at $-30{ }^{\circ} \mathrm{C}$. These blocks were tempered to $4{ }^{\circ} \mathrm{C}$ for 2 to $7 \mathrm{~d}$ before use. Perfect Italiano Semi Soft mozzarella cheese (Fonterra Brands Pty. Ltd., Melbourne, Australia) (named "supermarket cheese"), string cheese (Bega Original Stringers ${ }^{\circledR}$, Bega Cheese Ltd., Bega, Australia) and butter (Fonterra Brands, Auckland, New Zealand) were obtained from a local supermarket and stored at $4{ }^{\circ} \mathrm{C}$. The compositions of the cheese samples $(\mathrm{g} / 100 \mathrm{~g})$ were determined by Fonterra Research and Development Centre - factory cheese, 48.9 moisture, 22.1 fat, 24.5 protein, 1.26 salt and 3.06 ash; supermarket cheese, 47.8 moisture, 22.6 fat, 24.8 protein, 1.57 salt and 3.44 ash; string cheese, 46.5 moisture, 21.8 fat, 27.4 protein, 1.53 salt and 3.20 ash.

\subsection{Sample preparation for tensile testing}

\subsubsection{Elongated factory and supermarket cheese - standard procedure}

First $\sim 300 \mathrm{~g}$ cheese were heated to $60^{\circ} \mathrm{C}$ using a water bath and a leak proof stainless steel container. Excess liquid (always $<2 \mathrm{~g}$ ) was then decanted quickly. The melted cheese was placed near one end of a large aluminium metal plate $(750 \mathrm{~mm}$ × $250 \mathrm{~mm} \times 20 \mathrm{~mm})$ with aluminium strips (600 $\mathrm{mm} \times 40 \mathrm{~mm} \times 3 \mathrm{~mm}$ ) fixed on both sides as rails (to ensure minimum thickness of $3 \mathrm{~mm}$ ) and rolled manually towards the other end with a granite rolling pin. The thickness of the elongated cheese mass was uniform and $\sim 3-4 \mathrm{~mm}$. The metal plate, strips and rolling pin had been stored at $4^{\circ} \mathrm{C}$ for at least $14 \mathrm{~h}$. The cheese was rolled in one direction for a total elongation time of $120 \mathrm{~s}$ at a frequency of 10 rolls $\mathrm{min}^{-1}$. One roll means steady movement of the roller from one end of the cheese sheet to the other; each roll lasted for $6 \mathrm{~s}$. The rationale for elongating the cheese on a 
cooled, highly heat conductive surface with large thermal mass was to cool the cheese quickly in order to lock in any structure generated by elongation. The elongated cheese was covered with plastic wrap, stored for $2 \mathrm{~h}$ at $4{ }^{\circ} \mathrm{C}$ and cut with a scalpel into tensile samples using a template (Fig. 1) following the pattern shown in Fig. 2. This resulted in 16 longitudinal samples and 12 perpendicular samples per trial. The samples were individually wrapped in plastic and kept at $21{ }^{\circ} \mathrm{C}$ for at least $1 \mathrm{~h}$ before tensile testing. Variations from this standard procedure were made to explore the effects of experimental variables as explained in the results section.

\subsubsection{String cheese and original factory and supermarket cheese}

Slices 3-4 mm thick were cut longitudinally from the string cheese sticks. Samples were cut from these slices in longitudinal and perpendicular orientation to the stick axis. The string cheese sticks were only $\sim 15 \mathrm{~mm}$ diameter but the same template was still used for longitudinal samples. The perpendicular string cheese samples were short and were cut into a dumbbell shape without a template. A $300 \mathrm{~g}$ factory cheese block was cut into slices $\sim 3-4 \mathrm{~mm}$ thick. One of the slices was used to define the preferred orientation of the cheese fibres by tearing along these fibres. In this way the orientation of the template for cutting was determined. Two tensile samples were cut from each slice, one in each orientation. The procedure for obtaining supermarket cheese samples was exactly as for factory cheese. Samples were kept at $21{ }^{\circ} \mathrm{C}$ for at least $1 \mathrm{~h}$ before tensile testing.

\subsection{Tensile testing}

Tensile tests were carried out with a TA.XTplus Texture Analyser (Stable Micro Systems Ltd., Godalming, UK) in a laboratory controlled at $21{ }^{\circ} \mathrm{C}$. Crosshead speed was $2 \mathrm{~mm} \mathrm{~s}^{-1}$ and trigger force was 0.05 N. Serrated jaws were used and were tightened enough to prevent slippage. The initial dimensions of the smallest cross-section of each sample were measured with vernier calipers accurate to $0.01 \mathrm{~mm}$. The initial gap between the tensile jaws was $23 \mathrm{~mm}$ and the final gap $63 \mathrm{~mm}$ (except for the string cheese samples with perpendicular orientation). As expected the cheese samples all fractured in the narrow area of the dumbbell where stress would be greatest. 


\subsection{Data analysis and image acquisition}

Force-displacement data from tensile tests were converted into a true stress $(\sigma)$-Hencky strain

( $\varepsilon$ ) format using the following equations:

$\sigma=\frac{F(t)}{A(t)}$

$\varepsilon=\ln \frac{L(t)}{L_{O}}$

where $F(t)$ was force, $A(t)$ minimum cross sectional area, and $L(t)$ the length of the narrow mid part of the sample all at time $t$ and $L_{o}$ was the initial length of the narrow mid part of the sample (20 mm). A(t) was estimated as follows:

$A(t)=\frac{V}{L(t)}=\frac{V}{L_{O}+\Delta L}=\frac{L_{O} W_{O} T_{O}}{L_{O}+\Delta L}$

where $V$ was the volume of the narrow mid part of the cheese sample, calculated from the initial width and thickness $W_{o}$ and $T_{o}$ of the narrowest part of the cheese samples and $L_{o} . \Delta L$ is the displacement recorded. Charalambides, Williams and Chakrabarti (1995) similarly assumed constant volume during cheddar cheese testing and stated that this assumption was fairly accurate for cheese. Rohm, Jaros and deHaan (1997) experimentally demonstrated volume constancy during compression testing of Gouda cheese. The maximum modulus was the maximum slope before fracture in the $\sigma-\varepsilon$ diagram. The extent of anisotropy $\mathrm{R}$ was calculated as $\sigma($ longitudinal $) / \sigma($ perpendicular) and similarly for other parameters.

To check the assumptions made in calculation of $\mathrm{A}(\mathrm{t})$ (equation 3 ) 3 different tensile tests were filmed. A camera was fixed on a tripod with the front of the lens parallel to the front side of the cheese. A mirror at a $45^{\circ}$ angle and a small ruler were placed next to the sample. For each of the three tests images were analysed at 3 times - beginning, mid-test and immediately before fracture. Width and thickness were estimated for all images using the freeware image analysis tool ImageJ $1.47 \mathrm{t}$ (http://rsbweb.nih.gov). 
Confocal microscopy was used to determine the microstructure of cheese samples after various treatments including fracture. Cheese samples were cut and frozen $\left(-20^{\circ} \mathrm{C}\right)$ before being sectioned into $50 \mu \mathrm{m}$ slices on a microtome. Slices were immediately stained with $0.4 \%$ Nile red and $0.2 \%$ fast green (made in citifluor to minimise photobleaching) and covered with a coverslip. The sectioned samples were then stored at $4{ }^{\circ} \mathrm{C}$ for a minimum of $24 \mathrm{~h}$ before imaging. Images were taken using a confocal microscope (Leica DM6000B, Heidelberg, Germany) with excitation wavelengths of $488 \mathrm{~nm}$ and $633 \mathrm{~nm}$.

\subsection{Statistical analysis}

Significant differences $(\mathrm{P}<0.05)$ in the results were analysed by SPSS 12.0 software using single factor ANOVA and the Duncan post hoc test to compare means. All experiments with elongated supermarket and factory cheese were performed at least twice and sub-sampled, resulting in $n \geq 32$ longitudinal replicates and $n \geq 24$ perpendicular replicates, unless otherwise stated. For string cheese and original factory cheese at least 6 slices were cut from the cheese stick/block resulting in $n \geq 6$ longitudinal and perpendicular samples.

\section{Results}

\subsection{Tensile test basics}

Tensile force versus displacement curves for both longitudinal and perpendicular samples decreased in slope with stretching as the area of the sample decreased. $\sigma-\varepsilon$ curves (Fig. 3) showed a slope (tensile modulus) that slightly decreased with strain for perpendicular samples. For longitudinal samples the maximum modulus just before fracture was about 2.5 times the initial modulus. Longitudinal samples strain hardened during the tensile test.

$\sigma$ values calculated using $A(t)$ from image acquisition were in reasonable agreement with the corresponding $\sigma$ values calculated from equations 1 and 3. Image acquisition plus direct visual 
171 observation of fracture indicated that longitudinal samples usually fractured at roughly a $45^{\circ}$ angle 172 to the stretching direction. Mohr's circle analysis for pure tension indicates shear failure. In most 173 cases the fractured surface was rather stringy and in many cases it was shaped randomly. In 174 contrast, perpendicular samples fractured mainly at a $90^{\circ}$ angle to the stretching direction. Mohr's 175 circle analysis for pure tension indicates that this means tensile failure. Ak and Gunasekaran (1997) 176 similarly noted $45^{\circ}$ fracture angles for longitudinal samples and $90^{\circ}$ fracture angles for 177 perpendicular samples during tensile testing of mozzarella cheese.

\subsection{Reproducibility of the overall method}

Four trials were carried out at standard conditions using elongated factory cheese to check reproducibility (Table 1). The standard deviations were rather high. One reason for this is variability reason is the inherent variability in tensile fracture, because failure is related to the random occurrence of structural weaknesses or imperfections where cracks may initiate and propagate. Manski, van der Zalm, van der Goot and Boom (2008) and Grabowska, van der Goot and Boom (2012) produced fibrous materials from dense calcium caseinate-fat dispersions cross-linked by transglutaminase and similarly reported variability in their tensile measurements and attributed this to the fibrous nature of the samples with some samples breaking all at once and others in multiple stages. Fracture stress $\left(\sigma_{\mathrm{f}}\right)$ and fracture strain $\left(\varepsilon_{\mathrm{f}}\right)$ showed no significant differences between the 189 four trials, but some differences in modulus were observed at a 5\% significance level. These differences were not significant at a $10 \%$ level. In spite of the variability in the method significant differences were found between longitudinal and perpendicular samples and between sample treatments.

\subsection{Comparison of cheese types}

Table 2 shows tensile fracture behaviour for the five cheese types. String cheese had the highest 
supermarket cheese showed no significant anisotropy. Elongated supermarket cheese indicated significant anisotropy for $\varepsilon_{\mathrm{f}}$ but not for $\sigma_{\mathrm{f}}$ or maximum modulus. Elongated factory cheese showed pronounced anisotropic characteristics with large differences between longitudinal and perpendicular samples. All subsequent experiments were therefore carried out with elongated factory cheese.

\subsection{Effect of elongation conditions}

Fig. 4 shows $\sigma_{\mathrm{f}}$ versus sample location along the rolled cheese sheet. $\sigma_{\mathrm{f}}$ for longitudinal samples showed a maximum at $140 \mathrm{~mm}$. $\sigma_{\mathrm{f}}$ at $140 \mathrm{~mm}$ was significantly different from $\sigma_{\mathrm{f}}$ at $45 \mathrm{~mm}$ and 330 $\mathrm{mm}$ but not from $\sigma_{\mathrm{f}}$ at $235 \mathrm{~mm}$. The higher variability towards the ends of the rolled sheets suggested less uniformity in sample preparation. For the remaining experiments only the data for $140 \mathrm{~mm}$ and $235 \mathrm{~mm}$ for longitudinal samples ( $\mathrm{n}=8$ per trial) and 90, 185 and $280 \mathrm{~mm}$ for perpendicular samples $(n=9$ per trial) were used. This removed the end locations that had higher standard deviations and gave enough replicates for good statistical significance.

Anisotropic characteristics of elongated factory cheese were investigated for 5 different elongation temperatures (Fig. 5, Table 3). Elongation temperature was the cheese equilibration temperature before placing on the $4^{\circ} \mathrm{C}$ plate and elongating. For longitudinal samples $\sigma_{\mathrm{f}}$ increased with elongation temperature to a maximum at $70{ }^{\circ} \mathrm{C}$. Further increase of elongation temperature to $80^{\circ} \mathrm{C}$ resulted in a decrease of $\sigma_{\mathrm{f}}$. There was no statistical difference between the means for $\sigma_{\mathrm{f}}$ at 40 , 50 and $80^{\circ} \mathrm{C} . \sigma_{\mathrm{f}}$ at $60^{\circ} \mathrm{C}$ was significantly higher than these but at the same time significantly lower than $\sigma_{\mathrm{f}}$ at $70^{\circ} \mathrm{C}$. No significant differences were found between $\sigma_{\mathrm{f}}$ values for perpendicular samples.

For longitudinal samples $\sigma_{\mathrm{f}}$ decreased significantly with longer elongation times (Table 4). However, perpendicular samples showed no significant differences for $\sigma_{f}$ with elongation time. It appeared that the alignment of cheese fibres depended mainly on the first roll, which produced a flat cheese sheet. Further rolls generated only small changes in the length and thickness of the sheet. Consequently, the orientation of fibres and thus the degree of anisotropy are likely to be mainly 
221 influenced by the procedure when cheese is converted from a molten mass into a flat sheet. This largely took place during the first roll.

An elongation frequency of $3 \mathrm{~min}^{-1}$ produced a significantly lower $\sigma_{\mathrm{f}}$ and modulus than $10 \mathrm{~min}^{-1}$ for longitudinal samples (Table 5). An elongation frequency of $10 \mathrm{~min}^{-1}$ is close to the practical limit for manual rolling. The impact of elongation frequency might also be explained by the first roll. A faster first roll produces a significantly higher $\sigma_{\mathrm{f}}$. If the molten cheese was rolled too slowly a thick and poorly elongated cheese sheet resulted from the first roll. With further rolls the sheet did not change much as the deformability of the cheese decreased quickly with temperature reduction. Cracks would sometimes appear in the cheese sheet when trying to adjust after a slow first roll. It appears that there is an interplay between the rate of deformation and the rate of solidification. It is important to complete the first roll before the cheese has solidified too much.

\subsection{Effect of plate and storage temperature}

The metal plate and granite rolling pin were preconditioned to the experimental temperature for at least $14 \mathrm{~h}$ before rolling, and the elongated cheese sheet was then stored at the same temperature for $2 \mathrm{~h}$. To minimize moisture loss during storage at $21^{\circ} \mathrm{C}$ and $37^{\circ} \mathrm{C}$ the elongated cheese was covered with plastic film and also placed in a sealed snaplock plastic bag. $\sigma_{f}$ of both longitudinal and perpendicular samples decreased with increasing plate and storage temperature, although the differences between $\sigma_{\mathrm{f}}$ at $21^{\circ} \mathrm{C}$ and $37^{\circ} \mathrm{C}$ were not statistically significant (Table 6). Hypothesis 3 suggested that anisotropy would decrease on holding at an elevated temperature. However, although $\sigma_{f}$ reduced with storage temperature, longitudinal and perpendicular $\sigma_{\mathrm{f}}$ decreased by different amounts and anisotropy increased with increasing storage temperature. This experiment has not confirmed hypothesis 3 .

\subsection{Effect of remelting elongated cheese}

This experiment was designed to test hypothesis 2 . The standard procedure was followed, but after storing the elongated cheese at $4{ }^{\circ} \mathrm{C}$ for $2 \mathrm{~h}$ the elongated sheet was wrapped in plastic film, placed 
in a sealed snaplock bag to reduce moisture loss and stored at $60^{\circ} \mathrm{C}$ in an oven for $2 \mathrm{~h}$. The remelted sheet was then stored at $4^{\circ} \mathrm{C}$ for another $2 \mathrm{~h}$ before sample cutting and tensile testing. While remelting caused a large decrease in $\mathrm{R}$ values to 1.2 for $\sigma_{\mathrm{f}}$ and modulus and 1.1 for $\varepsilon_{\mathrm{f}}$, significant differences in means were observed between longitudinal and perpendicular samples for $\sigma_{\mathrm{f}}, \varepsilon_{\mathrm{f}}$ and modulus (Table 7). This shows that anisotropy is greatly reduced by remelting at $60^{\circ} \mathrm{C}$, but not completely removed. Longitudinal $\sigma_{\mathrm{f}}$ was reduced by around $50 \%$, but perpendicular $\sigma_{\mathrm{f}}$ increased by around 30\% (Fig. 4). An impact of moisture loss on the results is possible, but would not be directionally selective. Some condensation build up was observed inside the snaplock bag and this moisture had not completely reabsorbed after $2 \mathrm{~h}$ further storage at $4^{\circ} \mathrm{C}$. The moisture contents of the cheese before and after the $2 \mathrm{~h}$ storage at $60^{\circ} \mathrm{C}$ were not significantly different. After $2 \mathrm{~h}$ storage at $60^{\circ} \mathrm{C}$ the sheet length in the elongation direction had reduced by $15 \%$. This is an indicator that locked in strain was being relaxed. The longitudinal samples after remelting showed very little strain hardening.

\subsection{Confocal scanning laser microscopy}

Confocal micrographs of the original factory cheese showed clear structural anisotropy at this scale with longitudinal samples showing aligned fat phase between the protein strands (Fig. 6a) and perpendicular samples showing little alignment as we are looking end on at the aligned structure (Fig. 6b). The melted and elongated cheese similarly showed alignment for the longitudinal sample (Fig. 6c) but no alignment for the perpendicular sample (Fig. 6d). The fat phase in the elongated cheese showed more coalescence and less individual fat globules than the original factory cheese. The melted, elongated and remelted cheese showed no alignment for either the longitudinal (Fig. 6e) or perpendicular (Fig. 6f) samples. Confocal micrographs that show the fracture surface after tensile testing (Fig. 6g, h) indicate a high concentration of fat near or at the fracture surface suggesting that weak fat planes in the cheese may be the location of fracture initiation. 
271 Tensile testing of butter was attempted to determine whether the milkfat component of mozzarella 272 cheese contributes any tensile strength. The same method of sample preparation was used as for 273 original factory cheese but without choosing direction of cutting. Sample cutting and tensile testing 274 proved to be impossible at $21^{\circ} \mathrm{C}$ because the butter was too soft. The butter was therefore stored at $27544^{\circ} \mathrm{C}$ before cutting. The dumbbell samples were also stored at $4^{\circ} \mathrm{C}$ for at least $2 \mathrm{~h}$ before tensile 276 testing. They were then tested as quickly as possible in the $21^{\circ} \mathrm{C}$ laboratory. Of the 8 samples 277 prepared, 5 samples broke before testing or slipped out of the tensile grips. The remaining 3 278 samples had $\sigma_{\mathrm{f}}$ of $5.73 \pm 1.49 \mathrm{kPa}, \varepsilon_{\mathrm{f}}$ of $0.082 \pm 0.025$ and modulus of $49.6 \pm 15.1 \mathrm{kPa}$. The 279 samples were not isothermal during tensile testing with measured temperatures of $14^{\circ} \mathrm{C}$ to $20^{\circ} \mathrm{C}$. 280 Nevertheless these results showed that the tensile strength of milkfat at $21^{\circ} \mathrm{C}$ is very small.

\section{Discussion}

As milkfat has very low tensile strength at $21^{\circ} \mathrm{C}$, we conclude that the tensile properties of mozzarella cheese are largely due to the strength of the protein network. Tensile testing is therefore a good method to determine protein network strength and the effect of any processing changes. String cheese exhibited the highest degree of anisotropy with an R value for $\boldsymbol{\sigma}$ f of 6.0. String cheese is produced by extrusion into the shape of sticks (Chen et al., 2009) and shows a very fibrous character at a macroscopic level. The highly anisotropic character is therefore not surprising. Manski et al. (2008) reported R values for $\boldsymbol{\sigma}_{\mathbf{f}}$ up to 14.2 for their fibrous calcium caseinate materials formed by simultaneous shear and transglutaminase action showing that casein molecules are capable of producing highly anisotropic structures. The elongated supermarket cheese showed statistically significant anisotropy only for $\varepsilon_{\mathrm{f}}$ whereas elongated factory cheese was strongly anisotropic for all fracture properties. This might be because the supermarket cheese was described as semi-soft, indicating a high level of proteolysis (Chen et al., 2009). The effect of proteolysis on 
anisotropy depends on the degree of proteolysis and therefore is affected by the ripening time of mozzarella cheese.

The variation of $\sigma_{\mathrm{f}}$ with distance along the plate (Fig. 4) suggests that anisotropy increased with the force applied and the amount of flow induced while elongating. During the first roll at lower distances the amount of cheese in front of the roller was higher, requiring higher forces and more flow induction. At higher distances the thickness of the cheese sheet decreased continuously so that the required force and amount of flow decreased. Perhaps the higher rolling force and higher flow near the beginning of the plate resulted in better alignment of the samples at these distances.

Elongation temperature had a bigger impact on the degree of anisotropy than any other parameter. It is clear that elongation builds up or strengthens a network structure in the cheese. Presumably this strengthening is caused by increasing protein-protein interactions. Bryant and McClements (1998) note that hydrophobic protein-protein interactions increase in strength as temperature rises up to a maximum at about 60 to $70^{\circ} \mathrm{C}$, above which hydrophobic interactions begin to reduce again as the temperature is further increased. Hence, the increase in $\sigma_{\mathrm{f}}$ from 40 to $70{ }^{\circ} \mathrm{C}$ and the decrease in $\sigma_{\mathrm{f}}$ to $80^{\circ} \mathrm{C}$ are probably linked to changes in hydrophobic protein-protein interactions. An alternative explanation for the temperature effect is changes to the milk mineral system at high temperatures and various possibilities are discussed by Udyarajan, Horne and Lucey (2007). Calcium has higher affinity for $\alpha_{s 1}$-casein as the temperature increases. In addition calcium and phosphate in the serum phase of the cheese may form new insoluble calcium phosphate at higher temperature that could interact with the caseins. Commercially mozzarella cheese is usually stretched in hot water circulating at a temperature of approximately $72{ }^{\circ} \mathrm{C}$ (Chen et al., 2009), near the temperature where we found the greatest effect of elongation on $\sigma_{\mathrm{f}}$.

There are several indications of both strain hardening and work thickening of mozzarella

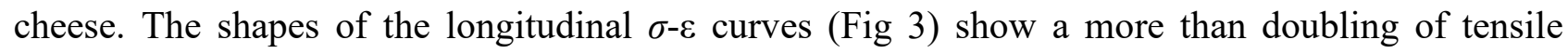
modulus between the start of the test and fracture, i.e. significant strain hardening. Perpendicular $\sigma$ $\varepsilon$ curves did not show strain hardening. Similar behaviour was reported by Manski, van der Goot 
and Boom (2007) for their tensile testing of fibrous materials produced by shearing fat-free calcium caseinate dispersions. Strain hardening was found in the fibre direction but not perpendicular to the fibre direction. Three trials under standard conditions were analysed to quantitate strain hardening. The ratio of maximum tensile modulus to initial modulus was $2.12 \pm 0.38(\mathrm{n}=24)$. Curve fitting showed two distinct regions on the $\sigma-\varepsilon$ curves. A linear model accurately fitted $\sigma-\varepsilon$ data up to a strain of about 0.4 . From 0.4 to a point near fracture, $\sigma-\varepsilon$ data was best modelled by an exponential curve. Clearly all the strain hardening is in the exponential part of the curve. Van Vliet (2008) notes that for bread dough there is often an exponential relationship between $\sigma$ and $\varepsilon$, though for bread dough this fits the whole $\sigma-\varepsilon$ curve rather than just the portion at high strain.

The reason for two distinct regions on the longitudinal $\sigma-\varepsilon$ curve is not clear. One possible explanation is that in the linear region, curves or bends in the fibre network are merely straightened. The concept of the straightening of curved strands was used by Lakemond and van Vliet (2008) to explain the fracture behaviour of acid skim milk gels. At higher strains where all the strands are now straight, the protein fibres must either stretch or move past one another, increasing the interactions between fibres. This may cause an increase in the strength of the protein network. The protein fibres in the longitudinal orientation also become progressively closer together because of the reducing cross-sectional area thus increasing interactions. In perpendicular samples, fibres would be pulled further apart, resulting in no strain hardening. Many biopolymers have been shown to strain harden both as single molecules, e.g. collagen, and also as network structures resulting in a significant body of biophysics literature on the topic, e.g. pectin (Vincent, Mansel, Kramer, Kroy \& Williams, 2013), rubber (Horgan \& Saccomandi, 2006). At the molecular level the strain hardening arises from limits to chain extensibility and to the "stickiness" of adjacent polymer chains. There are many reports of strain hardening of flour dough (e.g. Kokelaar et al., 1995; van Vliet et al., 1992; van Vliet, 2008).

Work thickening is also evident. The original factory cheese had $\sigma_{\mathrm{f}}$ of $36 \mathrm{kPa}$ parallel to the fibres and $33 \mathrm{kPa}$ perpendicular to the fibres (Table 2). After elongation the longitudinal $\sigma_{\mathrm{f}}$ had 
increased by 5.7 times to $204 \mathrm{kPa}$ and the perpendicular $\sigma_{\mathrm{f}}$ had increased by 2.1 times to $68 \mathrm{kPa}$. Presumably the elongation operation at $60^{\circ} \mathrm{C}$ has increased the strength of the casein network, i.e. increased protein-protein interactions. This stronger protein structure is aligned because of the elongation. $\sigma_{\mathrm{f}}$ of the remelted perpendicular samples is $84 \mathrm{kPa}$, about $30 \%$ higher than $\sigma_{\mathrm{f}}$ before remelting (Table 7), whereas $\sigma_{\mathrm{f}}$ of the remelted longitudinal samples is $105 \mathrm{kPa}$, about $50 \%$ lower than the $223 \mathrm{kPa} \sigma_{\mathrm{f}}$ before remelting (Table 7). One possible explanation is that the increased protein-protein interactions formed during elongation at $60^{\circ} \mathrm{C}$ are not destroyed by remelting, but the alignment is relaxed. Some of the increased protein-protein interactions thus increase $\sigma_{\mathrm{f}}$ in the remelted perpendicular samples. During mechanical flour dough development there are similarly significant increases in mechanical strength, or work thickening (e.g. Zheng, Morgenstern, Campanella \& Larsen, 2000).

Do these results help to explain the disagreement in the literature about anisotropy of mozzarella cheese? No significant anisotropy was found for original factory cheese when slices were cut from the block, but when this cheese was elongated strong anisotropy was observed (Table 2). Today, the final stages of continuous mozzarella cheese manufacture generally involve a stretching machine followed by a moulding step to form a block (Chen et al., 2009). We expect that the original cheese from stretching would be highly aligned and therefore anisotropic as it is transferred through a pipe to moulding. However, during moulding into blocks it is expected that this aligned structure will pack randomly with different orientations in different parts of the block. An aligned microstructure is retained in the confocal micrographs (Fig. 6a) but when a slice is cut and a large enough sample taken for tensile testing isotropic behaviour is observed. The length scale of anisotropy in the formed cheese block will vary between packing operations and might be expected to depend on the diameter of the cheese pipe feeding the block, any motion of the pipe around the space of the block, the presence of vibration to aid packing (eliminate air) and the packing rate. All previous studies that tested anisotropy of mozzarella cheese used samples cut from original cheese blocks. In the recent papers no anisotropy was observed as for our results with original factory cheese (Muliawan 
373 \& Hatzikiriakos, 2007; Olivares et al., 2009). However, in older papers anisotropy was clearly 374 demonstrated, e.g. Ak and Gunasekaran (1997). One possibility is that their cheese samples were 375 from smaller scale batch operations where large masses of cheese were placed into the moulds at 376 once leading to anisotropy on a macroscale. Part of our thinking was that if the cheese was packed 377 hot then relaxation of the structure could lead to the disappearance of anisotropy. However, the 378 confocal micrographs show clear alignment at the microscale so that is not the correct explanation.

\section{Conclusions}

Original factory mozzarella cheese showed no anisotropy on tensile testing but confocal micrographs indicated clear alignment in the structure at the microscale. The structure produced by melting and elongating the factory cheese was shown to be highly anisotropic both by tensile testing and by confocal microscopy. Elongation temperature had a significant impact on the extent of anisotropy. Remelting the mozzarella cheese after elongation gave a non-aligned structure that showed very little anisotropy. We suggest the disagreement on anisotropy in the literature is related to the method of packing the cheese into a block after the stretching stage of manufacture. During tensile testing elongated factory cheese showed strain hardening behaviour in the longitudinal direction but not in the perpendicular direction. Tensile testing was a good method to demonstrate and quantitate anisotropy and strain hardening in mozzarella cheese.

\section{Acknowledgements}

We are grateful to Fonterra Co-operative Group and the Ministry of Primary Industries for funding this work via the Dairy Primary Growth Partnership Programme in Food Structure Design. We thank Janiene Gilliland, Byron McKillop, Warwick Johnson, Garry Radford and Steve Glasgow for expert technical assistance. Discussions with Ton van Vliet, Thom Huppertz and Martin Williams were very useful in helping to understand the strain hardening data. 
Ak, M.M., \& Gunasekaran, S. (1997). Anisotropy in tensile properties of mozzarella cheese. Journal of Food Science, 62, 1031-1033.

Bryant, C.M., \& McClements, D.J. (1998). Molecular basis of protein functionality with special consideration of cold-set gels derived from heat-denatured whey. Trends in Food Science and Technology, 9, 143-151.

Cervantes, M.A., Lund, D.B., \& Olson, N.F. (1983). Effects of salt concentration and freezing on Mozzarella cheese texture. Journal of Dairy Science, 66, 204-213.

Charalambides, M.N., Williams, J.G. \& Chakrabarti, S. (1995). A study of the influence of ageing on the mechanical properties of cheddar cheese. Journal of Materials Science, 30, 3959-3967.

Chen, C., Wolle, D., \& Sommer, D. (2009). Mozzarella. In S. Clark \& F.W. Bodyfelt (Eds.), The sensory evaluation of dairy products (pp. 459-487). New York, NY, USA:Springer.

Grabowska, K.J., van der Goot, A.J. \& Boom, R.M. (2012). Salt-modulated structure formation in a dense calcium caseinate system. Food Hydrocolloids, 29, 42-47.

Horgan, C.O. \& Saccomandi, G. (2006). Phenomenological hyperelastic strain-hardening constitutive models for rubber. Rubber chemistry and technology, 79, 152-169.

Kindstedt, P.S. \& Fox, P.F. (1993). Effect of manufacturing factors, composition, and proteolysis on the functional characteristics of mozzarella cheese. Critical Reviews in Food Science and Nutrition, 33, 167-187.

Kokelaar, J.J., van Vliet, T. \& Prins, A. (1996). Strain hardening properties and extensibility of flour and gluten doughs in relation to breadmaking performance. Journal of Cereal Science, 24, 199-214.

Lakemond, C.M.M. \& van Vliet, T. (2008). Rheological properties of acid skim milk gels as affected by the spatial distribution of the structural elements and the interaction forces between them. International Dairy Journal, 18, 585-593. 
421 Lowe, L.L., Foegeding, A.E. \& Daubert, C.R. (2003). Rheological properties of fine-stranded whey 422 protein isolate gels. Food Hydrocolloids, 17, 515-522.

423 Manski, J.M., van der Goot, A.J. \& Boom, R.M. (2007). Formation of fibrous materials from dense 424 calcium caseinate dispersions. Biomacromolecules, 8, 1271-1279.

Manski, J.M., van der Zalm, E.E.J., van der Goot, A.J. \& Boom, R.M. (2008). Influence of process parameters on formation of fibrous materials from dense calcium caseinate dispersions and fat. Food Hydrocolloids, 22, 587-600.

McMahon, D.J., Fife, R.L. \& Oberg, C.J. (1999). Water partitioning in Mozzarella cheese and its relationship to cheese meltability. Journal of Dairy Science, 82, 1361-1369.

Muliawan, E.B., \& Hatzikiriakos, S.G. (2007). Rheology of mozzarella cheese. International Dairy Journal, 17, 1063-1072.

Muliawan, E.B., \& Hatzikiriakos, S.G. (2008). Rheology of mozzarella cheese: extrusion and rolling. International Dairy Journal, 18, 615-623.

Olivares, M.L., Zorrilla, S.E. \& Rubiolo, A.C. (2009). Rheological properties of mozzarella cheese determined by creep/recovery tests: effect of sampling direction, test temperature and ripening time. Journal of Texture Studies, 40, 300-318.

Pouzot, M., Nicolai, T., Benyahia, L. \& Durand, D. (2006). Strain hardening and fracture of heat-set fractal globular protein gels. Journal of Colloid and Interface Science, 293, 376-383.

Rohm, H., Jaros, D. \& deHaan, M. (1997). A video-based method for determination of average stress-strain relations in uniaxial compression of selected foods. Journal of Texture Studies, 28, 245-255.

Rohm, H., Ullrich, F., Schmidt, C., Lobner, J. \& Jaros, D. (2014). Gelation of cross-linked casein under small and large shear strain. Journal of Texture Studies, 45, 130-137.

Udyarajan, C.T., Horne, D.S. \& Lucey, J.A. (2007). Use of time-temperature superposition to study the rheological properties of cheese during heating and cooling. International Journal of Food Science and Technology, 42, 686-698. 
447 Van Vliet, T. (2008). Strain hardening as an indicator of bread-making performance: A review with 448 discussion. Journal of Cereal Science, 48, 1-9.

449 Van Vliet, T., Janssen, A.M., Bloksma, A.H. \& Walstra, P. (1992). Strain hardening of dough as a 450 requirement for gas retention. Journal of Texture Studies, 23, 439-460.

451 Vincent, R.R.R., Mansel, B.W., Kramer,A., Kroy, K. \& Williams, M.A.K. (2013). Micro452 rheological behaviour and nonlinear rheology of networks assembled from polysaccharides from 453 the plant cell wall. New Journal of Physics, 15, Article number 035002.

454 Zheng, H., Morgenstern, M.P., Campanella, O.H. \& Larsen, N.G. (2000). Rheological properties of 455 dough during mechanical dough development. Journal of Cereal Science, 32, 293-306. 
458 Fig. 1. Dumbbell-shaped template used for cutting cheese samples. Dimensions are in mm.

$459 \quad$ Fig.2. Sample cutting in longitudinal and perpendicular orientations.

460 Fig. 3. True stress versus Hencky strain for tensile testing of one longitudinal ( - ) and one 461 perpendicular (-- ) sample of factory mozzarella cheese prepared under standard conditions.

462 Fig. 4. True fracture stress versus distance along the rolled sheet for factory 463 mozzarella cheese prepared under standard conditions in the longitudinal ( $464 \rightarrow-)$ and perpendicular $(-\rightarrow-)$ orientations, and where standard conditions 465 were altered by holding the elongated cheese at $60{ }^{\circ} \mathrm{C}$ for $2 \mathrm{~h}$ before cooling 466 to $4{ }^{\circ} \mathrm{C}$ for $2 \mathrm{~h}$ then cutting dumbbell samples in longitudinal ( $\mathrm{x}$ ) and 467 perpendicular orientations $(\bullet)$. Error bars represent one standard deviation 468 from the mean.

469 Fig. 5. True fracture stress as a function of elongation temperature in the longitudinal $(\rightarrow-)$ and 470 perpendicular $(\rightarrow-)$ orientations and the corresponding ratio $R(-\rightarrow-)$. Error bars represent one 471 standard deviation from the mean.

472 Fig. 6. CSLM images of factory mozzarella cheese samples. Original cheese in the longitudinal (a) 473 and perpendicular (b) direction; elongated cheese in the longitudinal (c) and perpendicular (d) 474 direction; elongated and remelted cheese in the longitudinal (e) and perpendicular (f) direction; and 475 fractured edges of elongated cheese in the longitudinal $(\mathrm{g})$ and perpendicular $(\mathrm{h})$ direction.

476 Longitudinal samples were always viewed across the fibre direction whereas perpendicular samples 477 were viewed end on to the fibre direction. Red - fat; green - protein. 


\section{Table 1}

Reproducibility of the method -4 independent experimental trials under standard conditions

\begin{tabular}{|c|c|c|c|c|c|c|c|c|c|}
\hline \multirow{2}{*}{$\begin{array}{l}\text { Experimental } \\
\text { trial }\end{array}$} & \multicolumn{3}{|c|}{ Fracture stress $(\mathrm{kPa})$} & \multicolumn{3}{|c|}{ Fracture strain (-) } & \multicolumn{3}{|c|}{ Maximum modulus $(\mathrm{kPa})$} \\
\hline & Longitudinal & Perpendicular & $R$ & Longitudinal & Perpendicular & $R$ & $\begin{array}{l}\text { Longitudinal } \\
\end{array}$ & Perpendicular & $R$ \\
\hline 1 & $197 \pm 64^{\mathrm{A}}$ & $58 \pm 21^{\mathrm{B}}$ & 3.4 & $0.78 \pm 0.11^{\mathrm{A}}$ & $0.38 \pm 0.08^{\mathrm{B}}$ & 2.1 & $337 \pm 114^{\mathrm{A}}$ & $146 \pm 27^{\mathrm{C}}$ & 2.3 \\
\hline 2 & $215 \pm 31^{\mathrm{A}}$ & $72 \pm 18^{\mathrm{B}}$ & 3.0 & $0.75 \pm 0.05^{\mathrm{A}}$ & $0.41 \pm 0.08^{\mathrm{B}}$ & 1.8 & $418 \pm 72^{\mathrm{B}}$ & $170 \pm 21^{\mathrm{C}}$ & 2.5 \\
\hline 3 & $209 \pm 39^{A}$ & $71 \pm 17^{\mathrm{B}}$ & 2.9 & $0.74 \pm 0.08^{\mathrm{A}}$ & $0.40 \pm 0.08^{\mathrm{B}}$ & 1.9 & $393 \pm 80^{\mathrm{A}, \mathrm{B}}$ & $170 \pm 19^{C}$ & 2.3 \\
\hline 4 & $199 \pm 54^{\mathrm{A}}$ & $63 \pm 19^{\mathrm{B}}$ & 3.2 & $0.81 \pm 0.09^{\mathrm{A}}$ & $0.45 \pm 0.11^{\mathrm{B}}$ & 1.8 & $340 \pm 91^{\mathrm{A}}$ & $143 \pm 27^{\mathrm{C}}$ & 2.4 \\
\hline
\end{tabular}

Values are means with standard deviations from $n=16$ longitudinal samples and $n=12$ perpendicular samples for each trial. Means for the same parameter, e.g. fracture stress, with different superscript letters are significantly different $(P<0.05)$. 


\section{Table 2}

Effect of cheese type and cheese treatment

\begin{tabular}{|c|c|c|c|c|c|c|c|c|c|}
\hline \multirow[t]{2}{*}{ Cheese type } & \multicolumn{3}{|c|}{ Fracture stress $(\mathrm{kPa})$} & \multicolumn{3}{|c|}{ Fracture strain (-) } & \multicolumn{3}{|c|}{ Maximum modulus (kPa) } \\
\hline & Longitudinal & Perpendicular & $R$ & Longitudinal & Perpendicular & $R$ & Longitudinal & Perpendicular & $R$ \\
\hline String cheese & $204 \pm 21^{\mathrm{A}}$ & $34 \pm 6^{\mathrm{B}, \mathrm{C}}$ & 6.0 & $0.65 \pm 0.04^{\mathrm{A}}$ & $0.11 \pm 0.01^{\mathrm{D}}$ & 5.7 & $450 \pm 36^{\mathrm{A}}$ & $387 \pm 55^{\mathrm{C}}$ & 1.2 \\
\hline Orig. supermarket cheese & $34 \pm 8^{\mathrm{B}, \mathrm{C}}$ & $24 \pm 8^{\mathrm{B}}$ & 1.4 & $0.39 \pm 0.04^{\mathrm{B}}$ & $0.34 \pm 0.15^{\mathrm{B}}$ & 1.0 & $76 \pm 17^{\mathrm{B}}$ & $71 \pm 9^{\mathrm{B}}$ & 1.1 \\
\hline Elong. supermarket cheese & $60 \pm 12^{\mathrm{C}, \mathrm{D}}$ & $40 \pm 8^{\mathrm{B}, \mathrm{C}}$ & 1.5 & $0.76 \pm 0.07^{\mathrm{C}}$ & $0.60 \pm 0.06^{\mathrm{A}}$ & 1.3 & $88 \pm 21^{\mathrm{B}}$ & $65 \pm 13^{\mathrm{B}}$ & 1.4 \\
\hline Orig. factory cheese & $36 \pm 11^{\mathrm{B}, \mathrm{C}}$ & $33 \pm 12^{\mathrm{B}, \mathrm{C}}$ & 1.1 & $0.34 \pm 0.12^{\mathrm{B}}$ & $0.33 \pm 0.08^{\mathrm{B}}$ & 1.0 & $101 \pm 19^{\mathrm{B}}$ & $97 \pm 11^{\mathrm{B}}$ & 1.0 \\
\hline Elong. factory cheese & $204 \pm 47^{\mathrm{A}}$ & $68 \pm 18^{\mathrm{D}}$ & 3.0 & $0.76 \pm 0.09^{\mathrm{C}}$ & $0.41 \pm 0.08^{\mathrm{B}}$ & 1.9 & $383 \pm 95^{\mathrm{C}}$ & $162 \pm 24^{\mathrm{D}}$ & 2.4 \\
\hline
\end{tabular}

Values are means with standard deviations from the following: $n \geq 6$ longitudinal and perpendicular samples for both string cheese and original factory cheese, $n=3$ longitudinal and $\mathrm{n}=4$ perpendicular samples for original supermarket cheese; $\mathrm{n}=48$ longitudinal and $\mathrm{n}=36$ perpendicular samples for both elongated supermarket and factory cheese, from 3 trials. Means for the same parameter, e.g. fracture stress, with different superscript letters are significantly different $(P<0.05)$. 


\section{Table 3}

Effect of elongation temperature on tensile properties

\begin{tabular}{|c|c|c|c|c|c|c|c|c|c|}
\hline \multirow{2}{*}{$\begin{array}{l}\text { Elongation } \\
\text { temperature }\left({ }^{\circ} \mathrm{C}\right)\end{array}$} & \multicolumn{3}{|c|}{ Fracture stress $(\mathrm{kPa})$} & \multicolumn{3}{|c|}{ Fracture strain (-) } & \multicolumn{3}{|c|}{ Maximum modulus $(\mathrm{kPa})$} \\
\hline & Longitudinal & Perpendicular & $R$ & Longitudinal & Perpendicular & $R$ & Longitudinal & Perpendicular & $R$ \\
\hline 40 & $161 \pm 27^{\mathrm{A}}$ & $70 \pm 26^{\mathrm{D}}$ & 2.3 & $0.78 \pm 0.06^{\mathrm{A}, \mathrm{B}}$ & $0.43 \pm 0.12^{\mathrm{D}, \mathrm{E}}$ & 1.8 & $322 \pm 56^{\mathrm{A}}$ & $127 \pm 19^{\mathrm{D}}$ & 2.5 \\
\hline 50 & $174 \pm 23^{\mathrm{A}}$ & $57 \pm 14^{\mathrm{D}}$ & 3.0 & $0.79 \pm 0.05^{\mathrm{A}, \mathrm{B}}$ & $0.45 \pm 0.08^{\mathrm{D}}$ & 1.8 & $355 \pm 47^{\mathrm{A}}$ & $131 \pm 20^{\mathrm{D}}$ & 2.7 \\
\hline 60 & $223 \pm 31^{\mathrm{B}}$ & $64 \pm 18^{\mathrm{D}}$ & 3.5 & $0.80 \pm 0.07^{\mathrm{A}}$ & $0.38 \pm 0.07^{\mathrm{E}}$ & 2.1 & $421 \pm 69^{\mathrm{B}}$ & $161 \pm 23^{\mathrm{D}, \mathrm{E}}$ & 2.6 \\
\hline 70 & $259 \pm 60^{\mathrm{C}}$ & $64 \pm 19^{\mathrm{D}}$ & 4.0 & $0.73 \pm 0.08^{\mathrm{B}}$ & $0.32 \pm 0.07^{\mathrm{F}}$ & 2.3 & $494 \pm 114^{\mathrm{C}}$ & $216 \pm 42^{\mathrm{F}}$ & 2.3 \\
\hline 80 & $177 \pm 56^{\mathrm{A}}$ & $62 \pm 27^{\mathrm{D}}$ & 2.8 & $0.63 \pm 0.13^{\mathrm{C}}$ & $0.32 \pm 0.07^{\mathrm{F}}$ & 1.9 & $359 \pm 93^{\mathrm{A}, \mathrm{B}}$ & $192 \pm 41^{\mathrm{E}, \mathrm{F}}$ & 1.9 \\
\hline
\end{tabular}

Values are means with standard deviations from $n=16$ longitudinal and $n=18$ perpendicular samples for elongation temperatures of $40,50,70$ and $80{ }^{\circ} \mathrm{C}$, plus $\mathrm{n}=24$ longitudinal and $\mathrm{n}=27$ perpendicular samples for an elongation temperature of $60^{\circ} \mathrm{C}$. Means for the same parameter, e.g. fracture stress, with different superscript letters are significantly different $(P<0.05)$. 


\section{Table 4}

Effect of elongation time on tensile properties

\begin{tabular}{|c|c|c|c|c|c|c|c|c|c|}
\hline \multirow{2}{*}{$\begin{array}{l}\text { Elongation } \\
\text { time (s) }\end{array}$} & \multicolumn{3}{|c|}{ Fracture stress $(\mathrm{kPa})$} & \multicolumn{3}{|c|}{ Fracture strain (-) } & \multicolumn{3}{|c|}{ Maximum modulus $(\mathrm{kPa})$} \\
\hline & Longitudinal & Perpendicular & $R$ & Longitudinal & Perpendicular & $R$ & Longitudinal & Perpendicular & $R$ \\
\hline 18 & $242 \pm 21^{\mathrm{A}}$ & $66 \pm 17^{\mathrm{D}}$ & 3.7 & $0.80 \pm 0.05^{\mathrm{A}}$ & $0.39 \pm 0.08^{\mathrm{B}}$ & 2.0 & $467 \pm 52^{\mathrm{A}}$ & $180 \pm 32^{\mathrm{C}}$ & 2.6 \\
\hline 120 & $223 \pm 31^{\mathrm{B}}$ & $64 \pm 18^{\mathrm{D}}$ & 3.5 & $0.80 \pm 0.07^{\mathrm{A}}$ & $0.38 \pm 0.07^{\mathrm{B}}$ & 2.1 & $421 \pm 69^{\mathrm{B}}$ & $161 \pm 23^{C}$ & 2.6 \\
\hline 180 & $204 \pm 33^{\mathrm{C}}$ & $72 \pm 16^{\mathrm{D}}$ & 2.8 & $0.78 \pm 0.06^{\mathrm{A}}$ & $0.42 \pm 0.07^{\mathrm{B}}$ & 1.8 & $398 \pm 60^{\mathrm{B}}$ & $174 \pm 24^{\mathrm{C}}$ & 2.3 \\
\hline
\end{tabular}

Values are means with standard deviations from $n=16$ longitudinal and $n=18$ perpendicular samples for elongation times of 18 and $180 \mathrm{~s}$, plus $n=24$ longitudinal and $n=27$ perpendicular samples for an elongation time of $120 \mathrm{~s}$. Means for the same parameter, e.g. fracture stress, with different superscript letters are significantly different $(P<0.05)$. 


\section{Table 5}

Effect of elongation frequency on tensile properties

\begin{tabular}{|c|c|c|c|c|c|c|c|c|c|}
\hline \multirow{2}{*}{$\begin{array}{l}\text { Elongation } \\
\text { frequency }\left(\mathrm{min}^{-1}\right)\end{array}$} & \multicolumn{3}{|c|}{ Fracture stress $(\mathrm{kPa})$} & \multicolumn{3}{|c|}{ Fracture strain (-) } & \multicolumn{3}{|c|}{ Maximum modulus $(\mathrm{kPa})$} \\
\hline & Longitudinal & Perpendicular & $R$ & Longitudinal & Perpendicular & $R$ & Longitudinal & Perpendicular & $R$ \\
\hline 3 & $197 \pm 45^{\mathrm{A}}$ & $65 \pm 22^{C}$ & 3.0 & $0.77 \pm 0.07^{\mathrm{A}}$ & $0.39 \pm 0.10^{\mathrm{B}}$ & 2.0 & $370 \pm 88^{\mathrm{A}}$ & $166 \pm 32^{\mathrm{C}}$ & 2.2 \\
\hline 10 & $223 \pm 31^{\mathrm{B}}$ & $64 \pm 18^{C}$ & 3.5 & $0.80 \pm 0.07^{\mathrm{A}}$ & $0.38 \pm 0.07^{\mathrm{B}}$ & 2.1 & $421 \pm 69^{\mathrm{B}}$ & $161 \pm 23^{\mathrm{C}}$ & 2.6 \\
\hline
\end{tabular}

Values are means with standard deviations from $n=16$ longitudinal and $n=18$ perpendicular samples for an elongation frequency of 3 min ${ }^{-1}$, plus $n=24$ longitudinal and $\mathrm{n}=27$ perpendicular samples for an elongation frequency of $10 \mathrm{~min}^{-1}$. Means for the same parameter, e.g. fracture stress, with different superscript letters are significantly different $(P<0.05)$. 


\section{Table 6}

Effect of plate and storage temperature on tensile properties

\begin{tabular}{|c|c|c|c|c|c|c|c|c|c|}
\hline \multirow{2}{*}{$\begin{array}{l}\text { Plate temperature } \\
\left({ }^{\circ} \mathrm{C}\right)\end{array}$} & \multicolumn{3}{|c|}{ Fracture stress $(\mathrm{kPa})$} & \multicolumn{3}{|c|}{ Fracture strain (-) } & \multicolumn{3}{|c|}{ Maximum modulus $(\mathrm{kPa})$} \\
\hline & Longitudinal & Perpendicular & $R$ & Longitudinal & Perpendicular & $R$ & Longitudinal & Perpendicular & $R$ \\
\hline 4 & $223 \pm 31^{\mathrm{A}}$ & $64 \pm 18^{\mathrm{C}}$ & 3.5 & $0.80 \pm 0.07^{\mathrm{A}}$ & $0.38 \pm 0.07^{\mathrm{B}}$ & 2.1 & $421 \pm 69^{\mathrm{A}}$ & $161 \pm 23^{\mathrm{C}}$ & 2.6 \\
\hline 21 & $192 \pm 35^{\mathrm{B}}$ & $46 \pm 12^{\mathrm{D}}$ & 4.2 & $0.79 \pm 0.07^{\mathrm{A}}$ & $0.40 \pm 0.06^{\mathrm{B}}$ & 2.0 & $372 \pm 69^{\mathrm{B}}$ & $120 \pm 22^{\mathrm{D}}$ & 3.1 \\
\hline 37 & $179 \pm 39^{\mathrm{B}}$ & $41 \pm 18^{\mathrm{D}}$ & 4.4 & $0.77 \pm 0.09^{\mathrm{A}}$ & $0.38 \pm 0.07^{\mathrm{B}}$ & 2.0 & $353 \pm 67^{\mathrm{B}}$ & $112 \pm 43^{\mathrm{D}}$ & 3.2 \\
\hline
\end{tabular}

Values are means with standard deviations from $n=16$ longitudinal and $n=18$ perpendicular samples for plate and storage temperatures of 21 and $37{ }^{\circ} \mathrm{C}$, plus $\mathrm{n}=24$ longitudinal and $\mathrm{n}=27$ perpendicular samples for a plate and storage temperature of $4{ }^{\circ} \mathrm{C}$. Means for the same parameter, e.g. fracture stress, with different superscript letters are significantly different $(P<0.05)$. 


\section{Table 7}

Effect of remelting MC after elongation on tensile properties

\begin{tabular}{|c|c|c|c|c|c|c|c|c|c|}
\hline \multirow[t]{2}{*}{ Treatment } & \multicolumn{3}{|c|}{ Fracture stress $(\mathrm{kPa})$} & \multicolumn{3}{|c|}{ Fracture strain (-) } & \multicolumn{3}{|c|}{ Maximum modulus (kPa) } \\
\hline & Longitudinal & Perpendicular & $R$ & Longitudinal & Perpendicular & $R$ & Longitudinal & Perpendicular & $R$ \\
\hline Remelted MC & $105 \pm 23^{\mathrm{A}}$ & $84 \pm 16^{\mathrm{C}}$ & 1.2 & $0.52 \pm 0.06^{\mathrm{A}}$ & $0.47 \pm 0.07^{\mathrm{C}}$ & 1.1 & $232 \pm 48^{\mathrm{A}}$ & $199 \pm 36^{\mathrm{C}}$ & 1.2 \\
\hline Elongated MC & $223 \pm 31^{\mathrm{B}}$ & $64 \pm 18^{\mathrm{D}}$ & 3.5 & $0.80 \pm 0.07^{\mathrm{B}}$ & $0.38 \pm 0.07^{\mathrm{D}}$ & 2.1 & $421 \pm 69^{\mathrm{B}}$ & $161 \pm 23^{\mathrm{D}}$ & 2.6 \\
\hline
\end{tabular}

Values are means with standard deviations from $n=16$ longitudinal and $n=18$ perpendicular samples for remelted elongated MC, plus $n=24$ longitudinal and $\mathrm{n}=27$ perpendicular samples for MC elongated under standard experimental conditions. Means for the same parameter, e.g. fracture stress, with different superscript letters are significantly different $(P<0.05)$. 


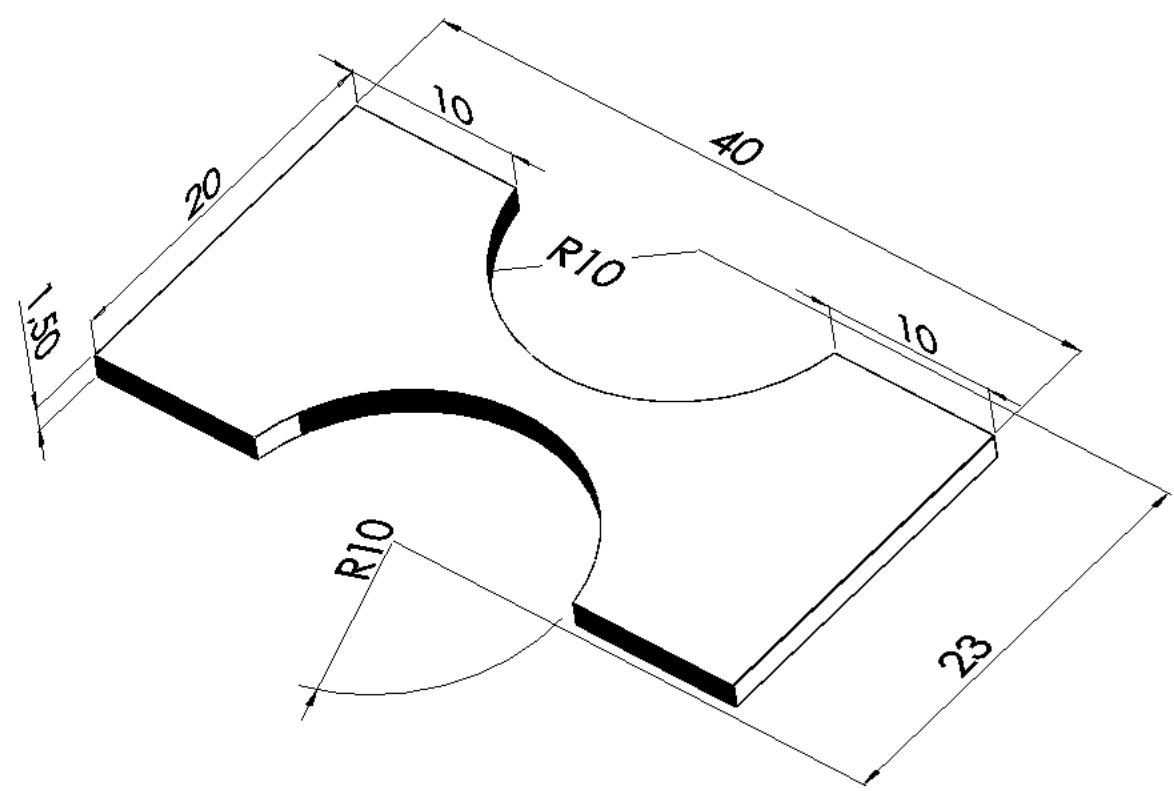

Fig. 1. Dumbbell-shaped template used for cutting cheese samples. Dimensions are in mm. 


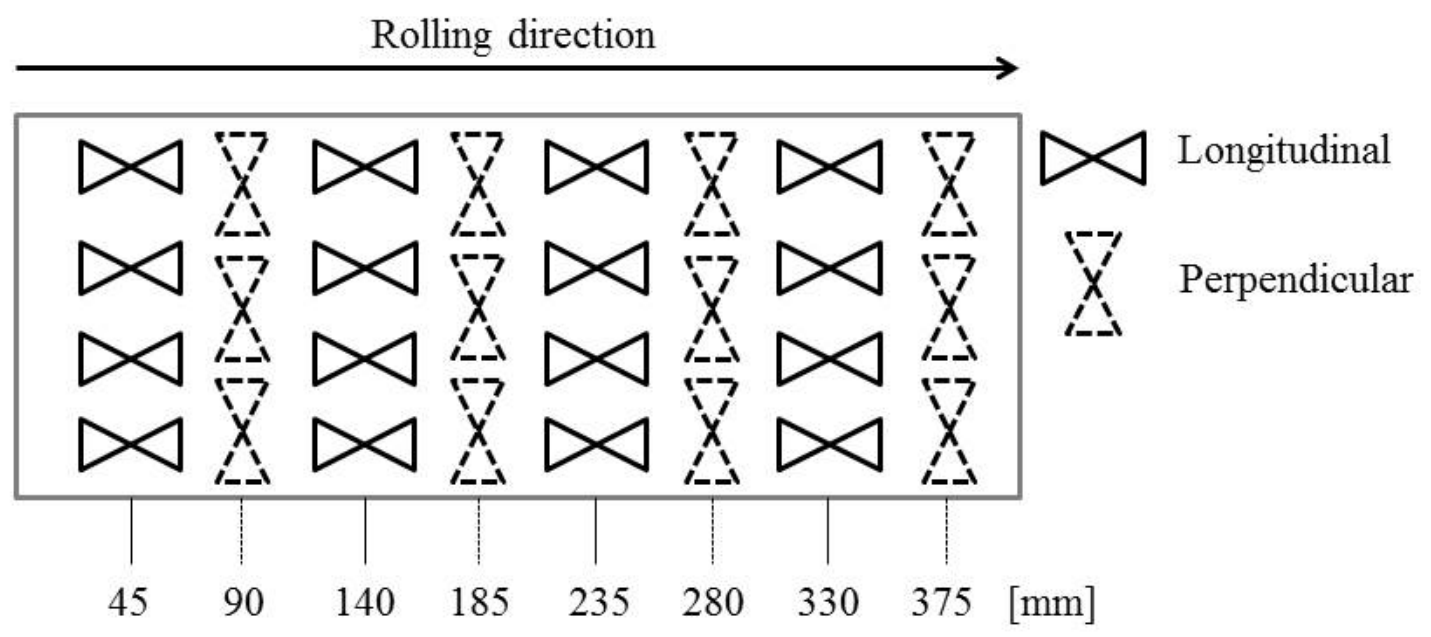

Fig. 2. Sample cutting in longitudinal and perpendicular orientations. 


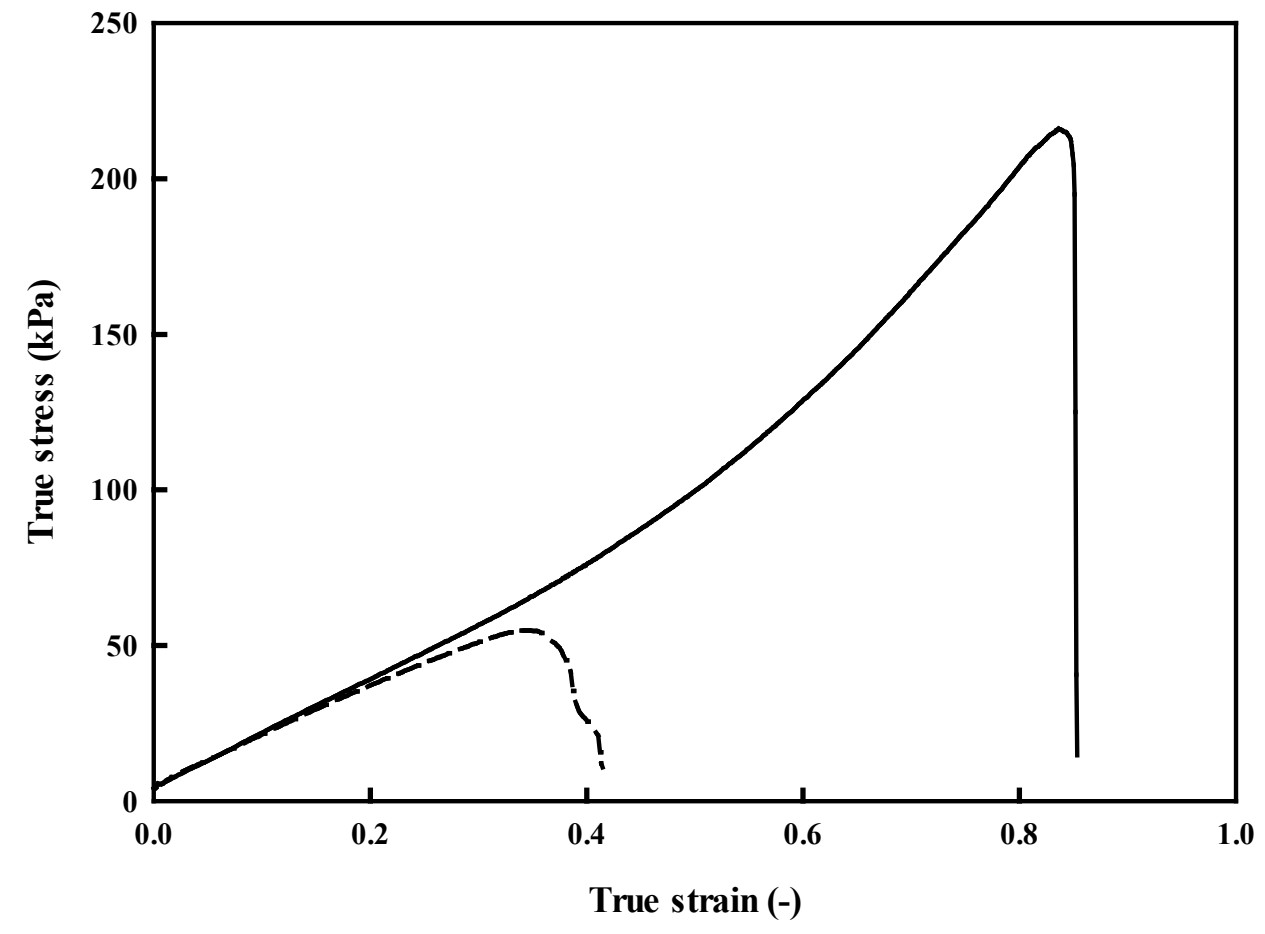

Fig. 3. True stress versus Hencky strain for tensile testing of one longitudinal (-) and one perpendicular (-- ) sample of factory mozzarella cheese prepared under standard conditions. 


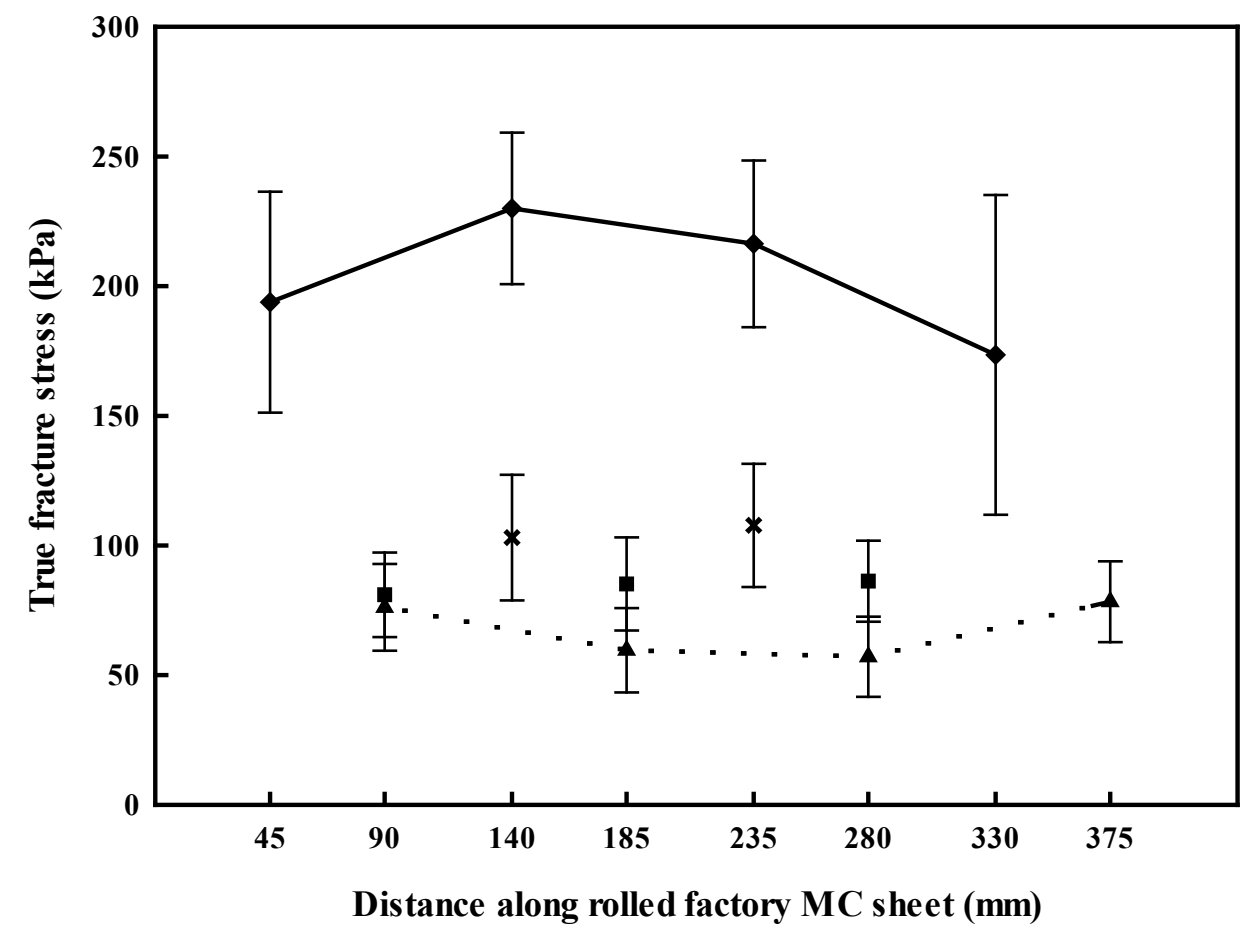

Fig. 4. True fracture stress versus distance along the rolled sheet for factory mozzarella prepared under standard conditions in the longitudinal $(\rightarrow)$ and perpendicular ( $-\rightarrow-)$ orientations, and where standard conditions were altered by holding the elongated cheese at $60{ }^{\circ} \mathrm{C}$ for $2 \mathrm{~h}$ before cooling to $4{ }^{\circ} \mathrm{C}$ for $2 \mathrm{~h}$ then cutting dumbbell samples in longitudinal $(\mathbf{x})$ and perpendicular orientations $(\bullet)$. Error bars represent one standard deviation from the mean. 


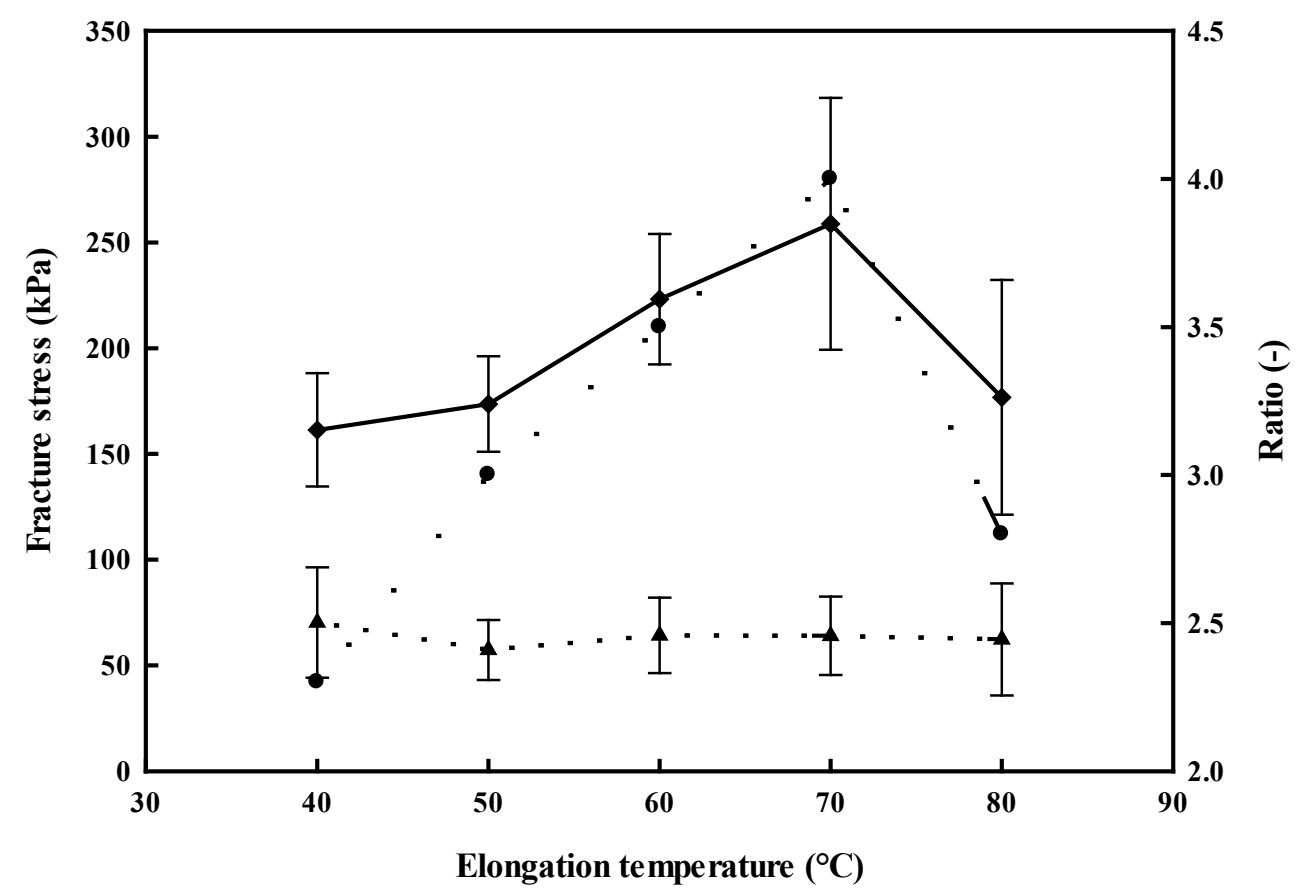

Fig. 5. True fracture stress as a function of elongation temperature in the longitudinal $(\rightarrow-)$ and perpendicular $(-\rightarrow-)$ orientations and the corresponding ratio $R(-\rightarrow-)$. Error bars represent one standard deviation from the mean. 

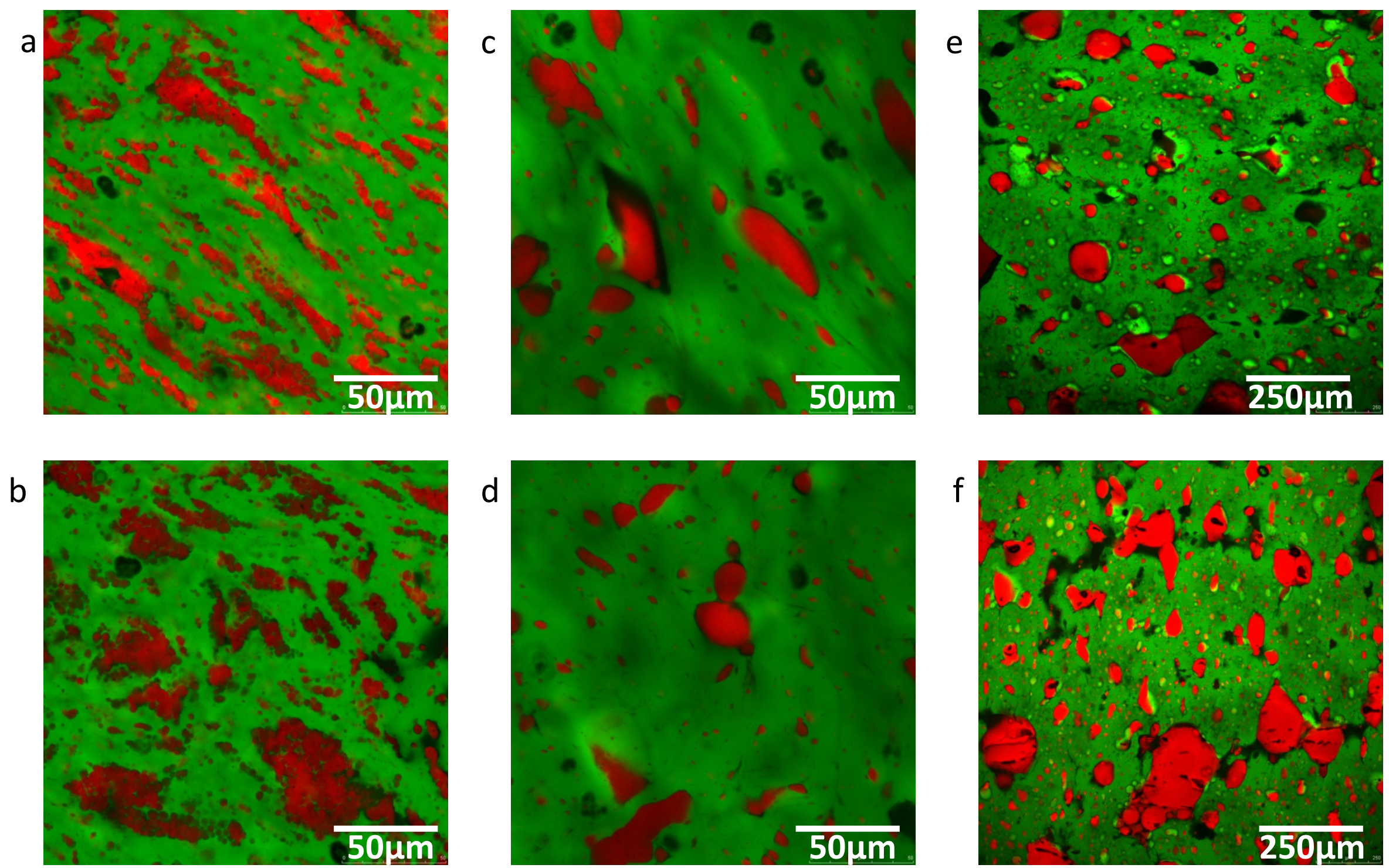


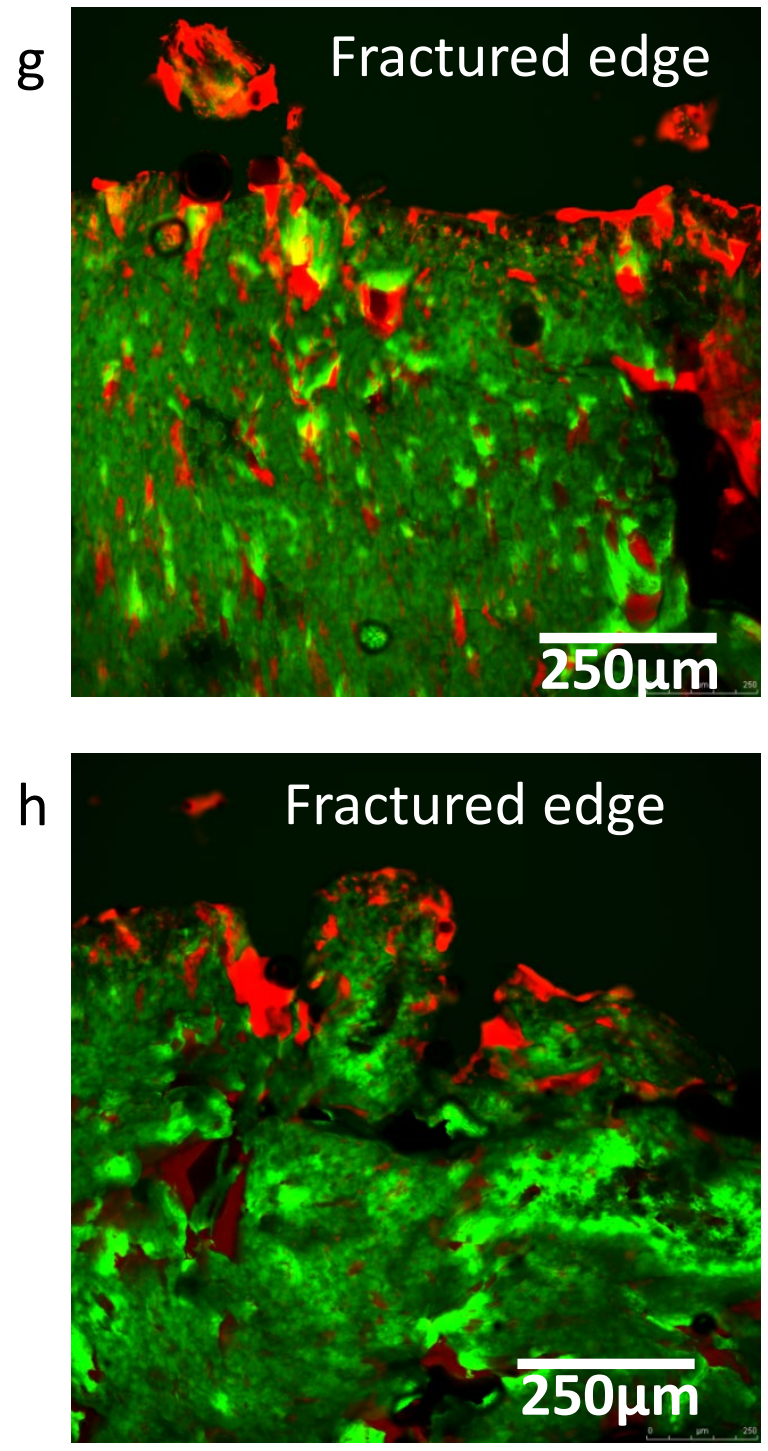

